Letter Report

\title{
Scoping Analysis of Gas Phase Transport from the Rulison Underground Nuclear Test
}

\author{
prepared by \\ Clay Cooper \\ Division of Hydrologic Sciences \\ Desert Research Institute \\ University and Community College System of Nevada
}

submitted to

Nevada Site Office

National Nuclear Security Administration

U.S. Department of Energy

Las Vegas, Nevada

May 6, 2004

The work upon which this report is based was supported by the U.S. Department of Energy under Contract \#DE-AC52-00NV13609; intended for limited distribution. 


\section{Introduction}

This letter report documents the results of a computer model to quantify the travel time of tritium (radioactive hydrogen) from an underground nuclear detonation in 1969 toward a proposed producing gas well located 1,500 feet (457 meters) away. The nuclear detonation was the result of a joint program between the U.S. Atomic Energy Commission (predecessor to the Department of Energy, DOE) and the petroleum industry to develop technology for nuclear stimulation of low permeability gas reservoirs not conducive to production by conventional means. Project Rulison was the second experiment under the program.

The Rulison site is located in west-central Colorado, approximately $64 \mathrm{~km}$ northeast of Grand Junction. A 40-kiloton nuclear explosive was placed at a depth of 2,568 m below the land surface in well R-E (also recognized as the Hayward \#25-95 (R-E)) located in the NE1/4SW1/4 Section 25, T7S, R95W, 6 ${ }^{\text {th }}$ P.M. in Garfield County. The detonation was within the Williams Fork Formation of the Mesaverde Group and occurred on September 10, 1969.

\section{Conceptual Model of Gas Flow and Radionuclide Transport}

Figure 1 shows the model domain in two-dimensions. A proposed gas well located 457 $\mathrm{m}$ from the R-E well would pump gas with a specified decline curve over a 30-year period. Production from this well induces both gas and liquid water flow through the Williams Fork Formation. Although the details of the well depth and production intervals are not known a priori, it is possible that the well would produce from a zone at the same depth of the detonation, which is assumed in the model. It is also assumed that the well will have multiple hydraulically fractured zones in the Williams Fork Formation, per current practice in the region. The hydraulically fractured, perforated interval at the nuclear test horizon is assumed to be $6.1 \mathrm{~m}$ thick (20 feet). The ambient pressure gradient is assumed to be much less than the gradient induced by pumping and is therefore assumed to be zero.

Flow is assumed to be largely horizontal as it is controlled entirely by the pumping well and the high-permeability fracture zone. Therefore, a reservoir thickness of $103 \mathrm{~m}$ was simulated, which was determined from the assumed multiple depths for the hydraulic fracturing. The simulation domain was organized such that the hydraulic fracturing would vertically straddle the formation, and that this depth was exactly opposite the detonation depth. The extent of the hydraulic fracture is assumed as $68 \mathrm{~m}$ vertically and $88 \mathrm{~m}$ horizontally away from the well and the intrinsic permeability of the fracture zone was estimated as $2.96 \times 10^{-14} \mathrm{~m}^{2}$ (30 millidarcy; md) with a porosity of 0.15 (Keith Blair, Presco, Inc., personal comm.). Intrinsic permeability of the undisturbed formation is $7.90 \times 10^{-18} \mathrm{~m}^{2}$ $(0.008 \mathrm{md})$ and the porosity is 0.112 . These values were determined from the mean values reported by Frank (1971). Gas saturation throughout the formation (including the hydraulically fractured zone and the fracture zone associated with the nuclear stimulation) was estimated as 0.6 (Keith Blair, Presco, Inc., personal comm.). The permeability was allowed to change as a function of the volumetric gas saturation. The van Genuchten equations were used for both relative permeability and capillary pressure. The corresponding parameters (residual saturation, van Genuchten parameters $m, n$ and $\alpha$ ) were from Carsel and Parrish (1988). Although developed for soils, relationships for a silty clay loam were used (as this texture has the lowest intrinsic permeability of their soil types) and scaled to the intrinsic permeabilities appropriate for the Williams Fork Formation. The simulations are not very 
sensitive to the choice of relative permeability and capillary pressure functions as the gas content changed little throughout time and throughout the model domain.

The fracture zone around the nuclear detonation was assumed to be $98 \mathrm{~m}$ tall and $238 \mathrm{~m}$ wide. The permeability is unknown - we assumed it to be the same as that of the zone of hydraulic fracturing around the production well $\left(2.96 \times 10^{-14} \mathrm{~m}^{2}\right)$.

The outer, vertical boundary condition (1,000 m away from the well) was prescribed as the formation pressure 21.87 MPa (3156 psi; Keith Blair, personal comm.). The horizontal boundary conditions above and below the simulation domain were prescribed as zero flux; this is to constrain flow largely to the horizontal direction and not allow for flow from the boundaries. This is considered an accurate physical description, as there are perforated/fractured zones above and below the one that is simulated, which would result in a horizontal streamline between adjacent perforated intervals in which no flow would cross. The boundary condition at the producing well was prescribed flux corresponding to the decay curve supplied by Presco, Inc.

\section{Numerical Model}

The TOUGH2 (Transport of Unsaturated Groundwater and Heat) integral finite difference simulator was used to implement the model as it handles three-dimensional, multiphase, multicomponent heat and mass transport through porous media in a fully coupled manner (Pruess et al., 1999). The code fully accounts for the movement of gaseous and liquid phases, their transport of latent and sensible heat, and phase transitions between liquid and vapor occurring under pressure, viscous, capillary, and gravity forces according to Darcy's law. The program provides options for specifying injection or withdrawal of energy (heat) and fluids. The equation of state module that was implemented (EOS7R) is capable of handling four components: water, air, solute and heat (although only isothermal flow was simulated). TOUGH2 is a DOE-sponsored code that has been used extensively to study heat and mass flow in geothermal reservoirs, saturated/unsaturated zones, and oil and gas reservoirs.

Several changes were made to the TOUGH2 program in order for it to correctly simulate the important processes. The EOS7R module assumes the gas phase to be air and air/water mixtures. This was easily changed to replace air properties with those of methane, which are important in the density and viscosity correlations. No changes were required with respect to phase partitioning. Values for Henry's constant of methane dissolution in water vary between $4.41 \times 10^{-10} \mathrm{~Pa}^{-1}\left(0^{\circ} \mathrm{C}\right)$ to $1.41 \times 10^{-10} \mathrm{~Pa}^{-1}\left(100^{\circ}\right)$. Since the values change by only a factor of three, and because the geothermal gradient relates to a temperature $\sim 100^{\circ} \mathrm{C}$ throughout much of the reservoir, the default value for air dissolution in water was used $\left(10^{-10} \mathrm{~Pa}^{-1}\right)$. This is not expected to have a significant effect on results, as the dissolution of methane in water is small.

In addition to radioactive decay, tritium fractionates isotopically between the liquid and gas phases. Fractionation is the preferential partitioning of an isotope (as opposed to a molecule, as described above) between the gas and liquid phases. (There is also fractionation within a phase, for example, tritium in water vapor and methane, but this has no effect on transport. Similarly, tritium fractionation between liquid water and water vapor is small due to the small amount of water vapor in the vapor phase.) Tritium will preferentially fractionate

between phases to form tritiated methane gas, $\mathrm{C}^{3} \mathrm{HH}_{3}$, and tritiated liquid water, ${ }^{3} \mathrm{HHO}$. The 
gas phase will favor light isotopes of methane $\left({ }^{1} \mathrm{H}\right)$ while the liquid phase will favor heavier isotopes $\left({ }^{3} \mathrm{H}\right)$. TOUGH2 does not handle isotope fractionation under equilibrium conditions. Implementation of isotope fractionation was begun in the TOUGH2 equation-of-state module (EOS7R), although it has not been fully tested. For this reason, fractionation of tritium between liquid water and methane was not included in these simulations, although it will be included in the full Rulison modeling project to begin in FY05. The results are still accurate, as fractionation acts to change concentrations by about a factor of two (the fractionation factor for tritium between methane and liquid water). Since the concentration field varies over ten orders of magnitude, the effect is not noticeable on the results. In addition, this uncertainty is well within the uncertainty in permeability, which is probably on the order of several orders-of-magnitude.

Initial conditions are presented in Table 1. The problem was formulated as twodimensional axisymmetric flow to a well. The solution domain was $1,000 \mathrm{~m}$ long ( $x$ direction) by $103 \mathrm{~m}$ high (z-direction). The initial source was estimated as 3,176 Curies (Ci) mixed with 30 bbls $\left(4.769 \times 10^{9} \mathrm{gr}_{2} \mathrm{O}\right)$ of water (Reynolds et al., 1970). This assumes that $40 \%$ of the tritium was amalgamated into the melt, which was the estimate at the Rio Blanco nuclear stimulation site (Toman and Tewes, 1972). This has decayed for 35 years; the amount remaining after this decay is calculated from the solution to $d M / d t=-\lambda M$ where $M$ is the initial mass and $\lambda$ is the decay constant (defined as $\lambda=\ln 2 / T_{1 / 2}$ where $T_{1 / 2}$ is the radioisotope half-life). After nearly three half-lives ( $T_{1 / 2}$ for tritium is 12.26 years), the radioactivity

Table 1. Initial conditions for simulations.

\begin{tabular}{|c|c|c|}
\hline Parameter & Value & Source \\
\hline Intrinsic permeability of undisturbed formation, $\mathrm{m}^{2}$ & $7.90 \times 10^{-18}$ & $\begin{array}{l}\text { Reynolds et al., } 1970 \text { and } \\
\text { Presco, pers. comm. }\end{array}$ \\
\hline Intrinsic permeability of hydraulic fracture zone, $\mathrm{m}^{2}$ & $2.96 \times 10^{-14}$ & Keith Blair, Presco \\
\hline Intrinsic permeability of nuclear stimulated zone, $\mathrm{m}^{2}$ & $2.96 \times 10^{-14}$ & $\begin{array}{l}\text { Assumed same as hydraulic } \\
\text { fracture zone }\end{array}$ \\
\hline Porosity, undisturbed & 0.112 & Various reports \\
\hline Porosity, hydraulic fracture & 0.15 & Keith Blair, Presco \\
\hline Porosity, nuclear stimulated zone & 0.15 & $\begin{array}{l}\text { Assumed same as hydraulic } \\
\text { fracture zone }\end{array}$ \\
\hline Relative permeability & van Genuchten func. & Carsel and Parrish, 1988 \\
\hline Capillary pressure curve & van Genuchten func. & Carsel and Parrish, 1988 \\
\hline Reservoir Pressure, $\mathrm{Pa}$ & $21.87 \mathrm{MPa}$ & Toman, 1975 \\
\hline Gas saturation & 0.6 & $\begin{array}{l}\text { CER Geonuclear; Toman and } \\
\text { Tewes, } 1972\end{array}$ \\
\hline${ }^{3} \mathrm{H}$ radioactivity, $\mathrm{Ci}$ & 1447 & Reynolds et al., 1970 \\
\hline Diffusion coefficient, ${ }^{3} \mathrm{H}$ in methane, $\mathrm{m}^{2} \mathrm{~s}^{-1}$ & $7.26 \times 10^{-5}$ & Cussler, 1997 \\
\hline Diffusion coefficient, ${ }^{3} \mathrm{H}$ in liquid water, $\mathrm{m}^{2} \mathrm{~s}^{-1}$ & $3.47 \times 10^{-9}$ & Mills, 1973 \\
\hline Diffusion coefficient, He in methane, $\mathrm{m}^{2} \mathrm{~s}^{-1}$ & $6.75 \times 10^{-5}$ & Cussler, 1997 \\
\hline Diffusion coefficient, He in liquid water, $\mathrm{m}^{2} \mathrm{~s}^{-1}$ & $6.28 \times 10^{-9}$ & Cussler, 1997 \\
\hline Diffusion coefficient, $\mathrm{CH}_{4}$ in liquid water, $\mathrm{m}^{2} \mathrm{~s}^{-1}$ & $1.49 \times 10^{-9}$ & Cussler, 1997 \\
\hline${ }^{3} \mathrm{H}$ half-life, yr & 12.26 & Parrington et al., 1996 \\
\hline
\end{tabular}

Diffusion coefficients measured or estimated for $25^{\circ} \mathrm{C}$ 
is 0.138 of the initial value. Therefore, the initial radioactivity for the simulations (i.e., assuming that pumping began in 2004) is $439 \mathrm{Ci}$. The initial concentration is therefore is 3.4 $\mathrm{x} 10^{7} \mathrm{pCi} / \mathrm{l}$ in the liquid phase. The tritium radioactivity at the start of the simulations (439 Ci) calculates to a mass fraction of tritium in the liquid phase (the input format for TOUGH2) of $9.59 \times 10^{-12}$. The simulator then partitions tritium between the liquid and gas phases in the first time step based upon Henry's law.

The decline curve (provided by Keith Blair, Presco, Inc.) is presented in Table 2. The decline curve is for a well typically producing from ten $20-\mathrm{ft}$ zones. Therefore, the values were divided by ten (since the model simulates production from one zone) and converted to $\mathrm{kg} \mathrm{sec}^{-1}$ for each month (assuming a constant gas density of $0.625 \mathrm{~kg} \mathrm{~m}^{-3}$ ). The well was estimated to produce for 30 years; the final value in the table was kept constant for the remaining 20 years of production.

Table 2. Typical decline curve for simulations. Values are in thousands of cubic feet of gas (MCFG) for the entire month.

\begin{tabular}{rrrrrrrrrrrrr}
\hline Year & \multicolumn{1}{c}{ Jan } & \multicolumn{1}{c}{ Feb } & \multicolumn{1}{c}{ Mar } & \multicolumn{1}{c}{ Apr } & \multicolumn{1}{c}{ May } & \multicolumn{1}{c}{ Jun } & \multicolumn{1}{c}{ Jul } & \multicolumn{1}{c}{ Aug } & \multicolumn{1}{c}{ Sep } & \multicolumn{1}{c}{ Oct } & \multicolumn{1}{c}{ Nov } & \multicolumn{1}{c}{ Dec } \\
\hline 1992 & 39,000 & 35,400 & 31,350 & 24,000 & 21,000 & 18,600 & 16,500 & 15,900 & 15,000 & 14,400 & 14,100 & 13,950 \\
1993 & 11,550 & 11,550 & 11,550 & 10,800 & 10,800 & 10,800 & 10,260 & 10,260 & 10,260 & 9,750 & 9,750 & 9,750 \\
1994 & 9,000 & 9,000 & 9,000 & 8,250 & 8,250 & 8,250 & 7,860 & 7,860 & 7,860 & 7,500 & 7,500 & 7,500 \\
1995 & 7,050 & 7,050 & 7,050 & 6,600 & 6,600 & 6,600 & 6,450 & 6,450 & 6,450 & 6,300 & 6,300 & 6,300 \\
1996 & 6,150 & 6,150 & 6,150 & 6,000 & 6,000 & 6,000 & 5,850 & 5,850 & 5,850 & 5,700 & 5,700 & 5,700 \\
1997 & 5,550 & 5,550 & 5,550 & 5,400 & 5,400 & 5,400 & 5,250 & 5,250 & 5,250 & 5,100 & 5,100 & 5,100 \\
1998 & 4,950 & 4,950 & 4,950 & 4,800 & 4,800 & 4,800 & 4,710 & 4,710 & 4,710 & 4,650 & 4,650 & 4,650 \\
1999 & 4,560 & 4,560 & 4,560 & 4,500 & 4,500 & 4,500 & 4,380 & 4,380 & 4,380 & 4,260 & 4,260 & 4,260 \\
2000 & 4,140 & 4,140 & 4,140 & 4,050 & 4,050 & 4,050 & 3,900 & 3,900 & 3,900 & 3,810 & 3,810 & 3,810 \\
2001 & 3,690 & 3,690 & 3,690 & 3,600 & 3,600 & 3,600 & 3,450 & 3,450 & 3,450 & 3,300 & 3,300 & 3,300 \\
\hline
\end{tabular}

The TOUGH2 simulator was run with variable time stepping; an initial time-step of 1 second was allowed to increase to a maximum of $10^{9}$ seconds. The convergence criterion for relative error was set at $10^{-5}$ for all simulations. Precision was checked by running several simulations with the relative error set at $10^{-6}$; the difference in results was not discernible.

\section{Results and Discussion}

Figure 2a shows the initial condition. The tritium source is located $458 \mathrm{~m}$ from the proposed pumping well. Figure 2b, c, and d show gas phase concentrations at 10 years, 25 years, and 35 years after the detonation. Transport of tritium in the gas phase is due solely to diffusion, as pumping does not begin until 35 years after the detonation (the length of time between the detonation and pumping of the proposed well in the year 2004). The slight asymmetry of the concentration field is due to the nonuniform gridding scheme on either side of the source. Figures 3a, 3b, and 3c show tritium concentrations in the gas phase for 45 years, 55 years, and 65 years after the detonation (corresponding to 10, 20, and 30 years of pumping, respectively). Results show that for these initial and boundary conditions, a concentration of $1 \mathrm{pCi} / \mathrm{L}$ nearly reaches the drilling exclusion zone after 10 years of 
pumping. Figure 3d shows mass fraction of tritium in the liquid (water) phase. The contours are bounded at the low end by the same value, $1.04 \times 10^{-19}$, which is equivalent to $1 \mathrm{pCi}$ per liter. The uppermost values are different: since tritium partitions differently in liquids and gases, the upper value is the maximum amount that each phase could contain based upon the initial mass fraction. For the most part, tritium migration is unaffected by pumping and controlled by diffusion in the gas phase, as the pumping rate is so low. After 30 years of pumping, the edge of the tritium "plume" has traveled approximately 180 meters, but is still 280 meters from the production well.

Figures 2 and 3 show that the center of the plume remains stationary, while the tritium radioactively decays. The radioactive decay is most obvious in the decline in concentration at the center of the plume, but decay is also responsible for the slowing of the growth of the plume. Note that there is little lateral migration from 45 years after the Rulison test.

Figure 4 is a similar simulation, but with radioactive decay turned off. Results are shown for 10, 20, and 30 years of pumping. This is what would be expected for a radionuclide with a very long half-life or some other, stable, constituent. The tritium mass fraction fields are similar to those of Figure 3, although they extend about $100 \mathrm{~m}$ farther in all directions. The difference between Figures 3 and 4 is due to the effect of radioactive decay on reducing the tritium mass shown in Figure 3. In both cases, diffusion is the process controlling tritium migration, as seen by the fairly uniform concentration fields.

To see the effect of pumping, the pumping rate was increased to a constant value of 0.1 $\mathrm{kg} \mathrm{sec}^{-1}$ (one order of magnitude greater than the highest pumping rate input for the decline curve). Figure 5 shows the results of a simulation with a single permeability of $2.96 \times 10^{-14}$ $\mathrm{m}^{2}$ throughout the domain. This permeability is the same as that given to the fracture zones around the producing well and the emplacement hole R-E. Flow is seen to sweep throughout the domain, carrying tritium in the gas phase. The tritium concentration field in the liquid phase shown in Figure $5 d$ corresponds with the concentration field in the gas phase, although not due to liquid phase (water) movement. Rather, the tritium component of the gas phase is in constant equilibrium with the liquid phase (e.g., Henry's law partitioning) and therefore becomes dissolved in the gas phase due to its volatility and not due to liquid-phase transport per se.

\section{References}

Carsel, R.F. and R.S. Parrish, 1988. Developing joint probability distributions of soil water retention characteristics. Water Resour. Res., 24(5), 755-769.

Cussler, E.L., 1997. Diffusion Mass Transfer in Fluid Systems, $2^{\text {nd }}$ edition, Cambridge University Press, 580 pp.

Frank, G.W., 1971. The nuclear stimulation of a natural gas reservoir - Project Rulison. World Petroleum Congress, 8(3), 355-363.

Mills, R., 1973. Self-diffusion in normal and heavy water in the range 1-45․ J. Physical Chem., 77(5), 685-688.

Parrington, J.R., H.D. Knox, S.L. Breneman, E.M. Baum and F. Feiner, 1996. Nuclides and Isotopes, Fifteenth Edition. General Electric Co., San Jose, California, 64p. 
Pruess, K., C. Oldenburg and G. Moridis, 1999. TOUGH2 User's Guide, Version 2.0, LBNL43134, Berkeley, California.

Reynolds, M., Bray B.G. and R.L. Mann, 1970. Project Rulison: A status report, Society of Petroleum Engineers of AIME, paper no. SPE 3191, 17 pp.

Toman, J. and H.A. Tewes, 1972. Project Rio Blanco: Phase I Technical Studies, UCID15968, Lawrence Livermore Laboratory, 138 pp.

Toman, J., 1975. Production test data and preliminary analysis of top chimney/cavity. Nuclear Technology, 27, 692-704. 


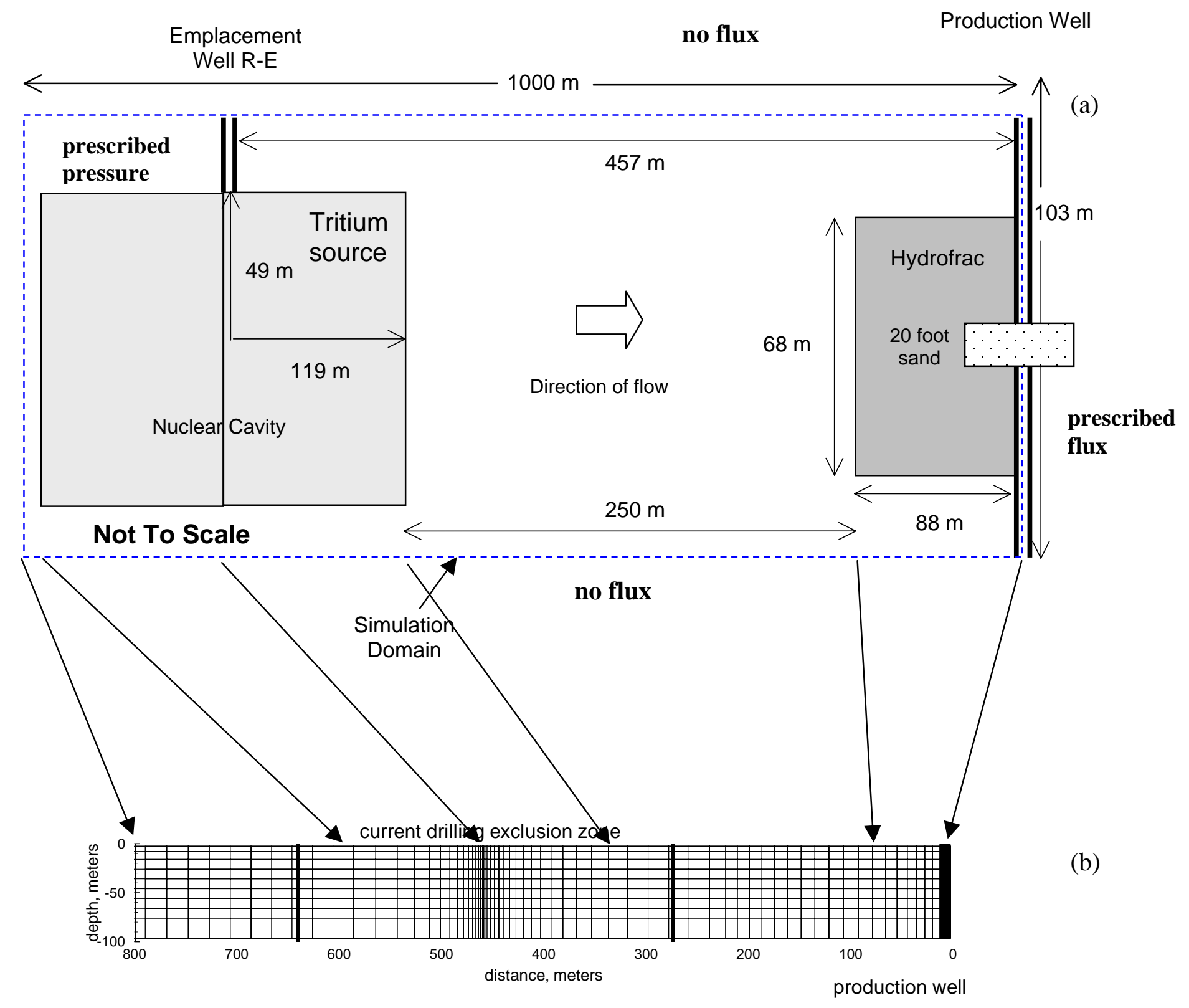

Figure 1. Model formulation for gas flow and tritium transport to a pumping well (a), and integral finite difference grid for simulations (b). 

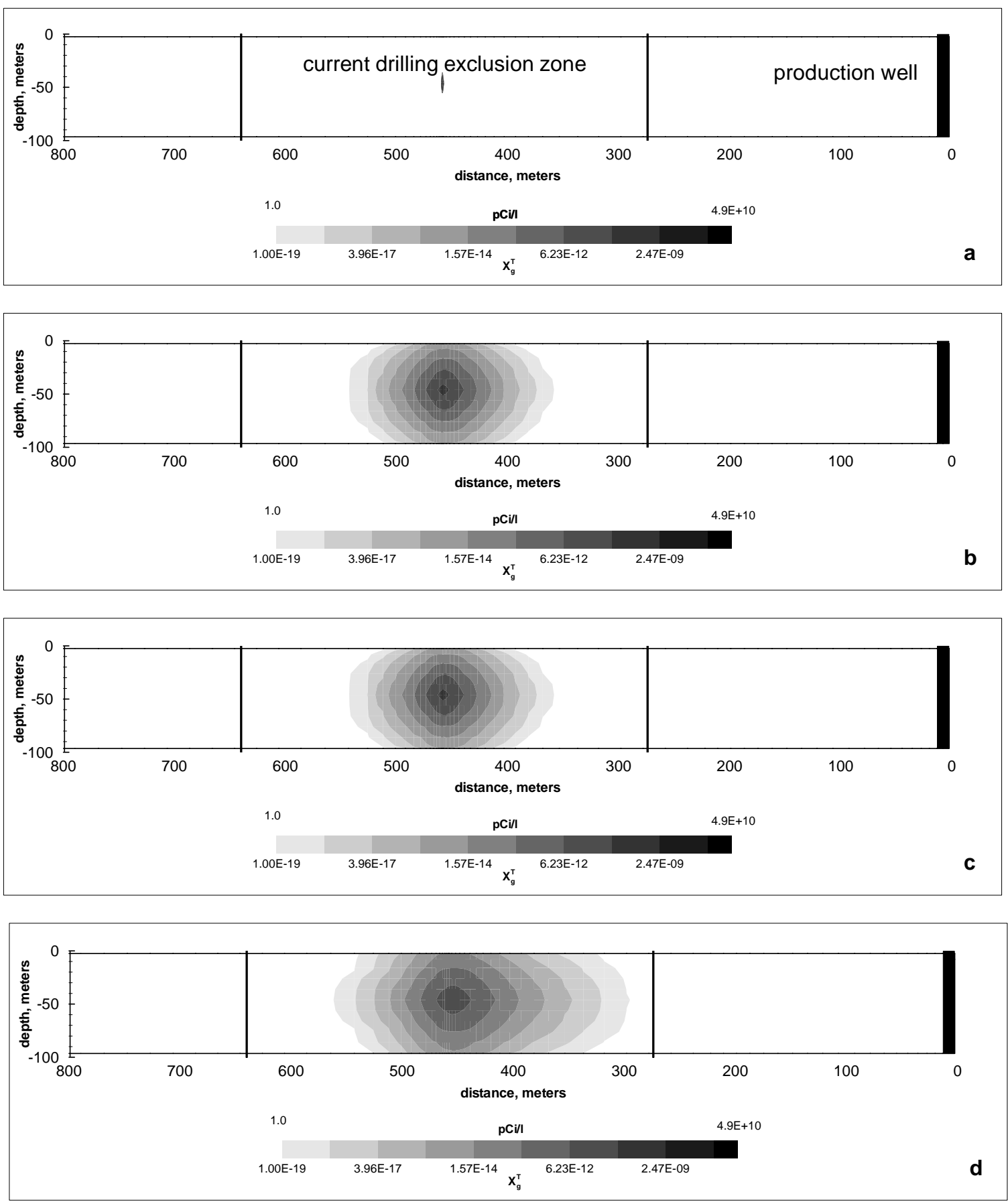

Figure 2. Tritium concentration in the gas phase as mass fraction (kg tritium / $\mathrm{kg}$ gas) and picoCuries per liter at (a) the start of the simulation, (b) 10 years, (c) 25 years, and (d) 35 years after the nuclear detonation. The heavy vertical bars show the limit of the current drilling exclusion zone. 

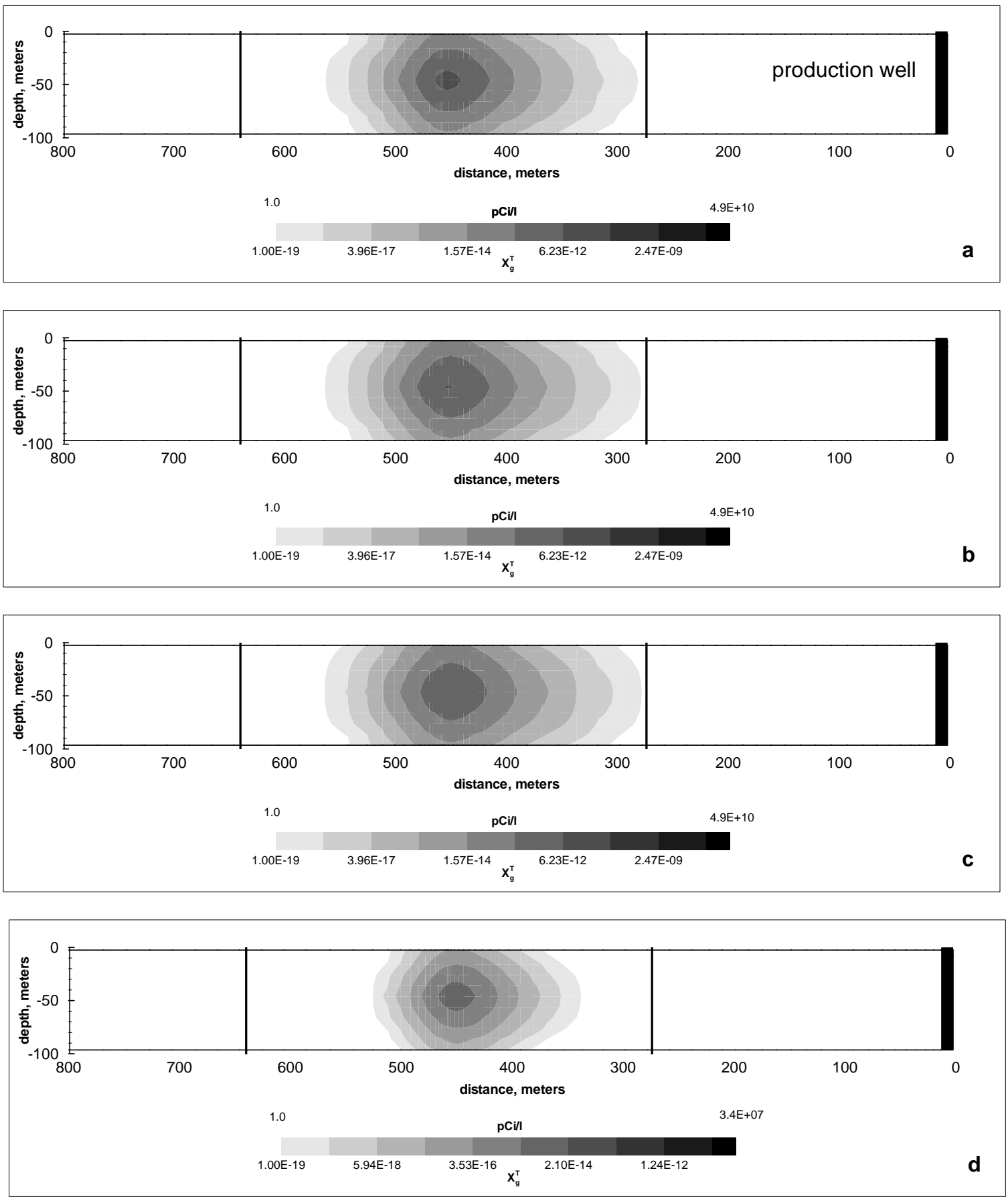

Figure 3. Tritium concentration in the gas phase for the same simulation as in Figure 2 at (a) 45 years, (b) 55 years, (c) and 65 years after the nuclear detonation. Pumping began 35 years after the detonation. Figure (d) shows the concentration of tritium in the liquid phase 65 years after the detonation. 

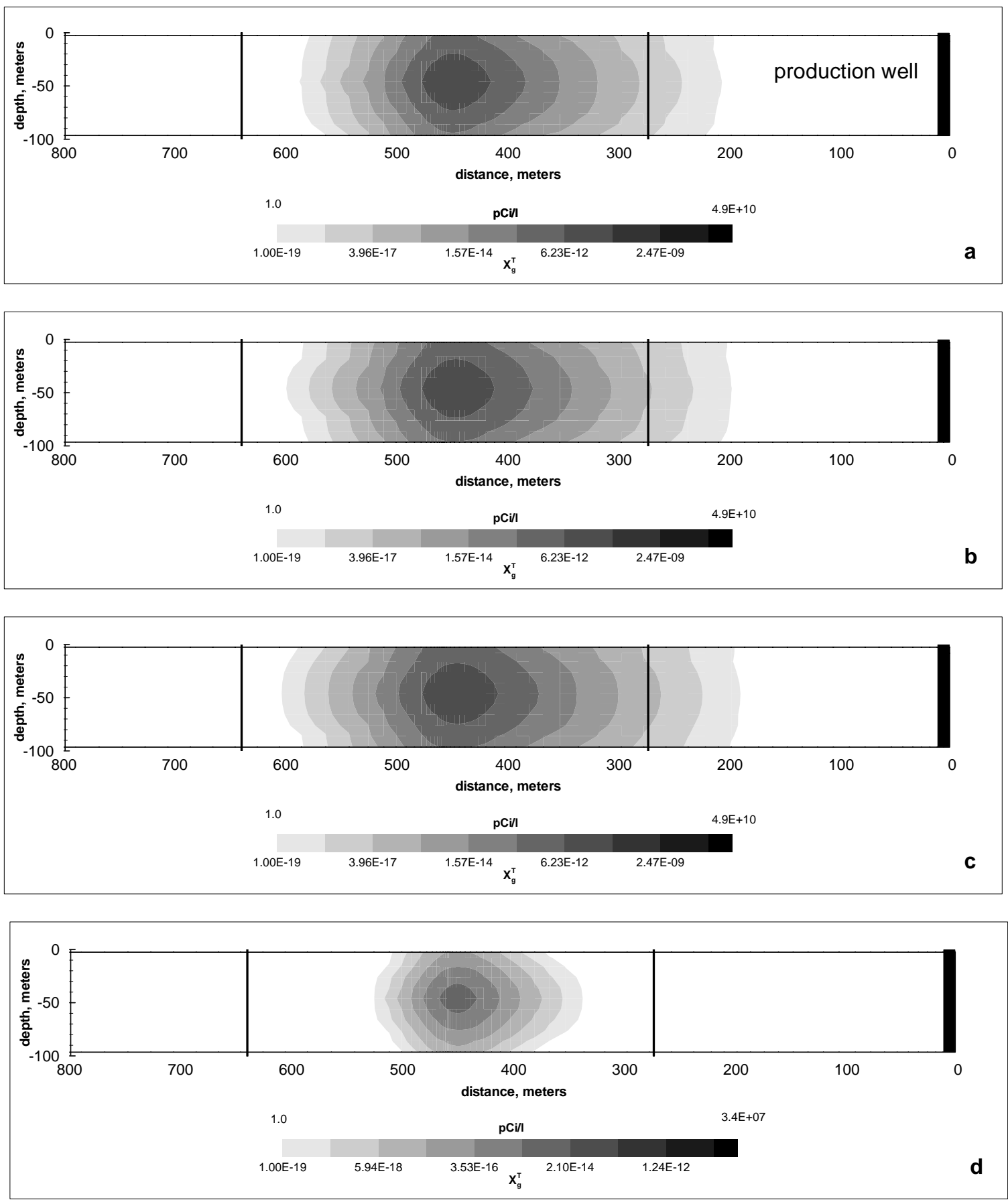

Figure 4. Tritium concentration in the gas phase after (a) 45 years, (b) 55 years, and (c) 65 years after the detonation with no radioactive decay. Figure (d) is the concentration of tritium dissolved in the liquid phase after 65 years. 

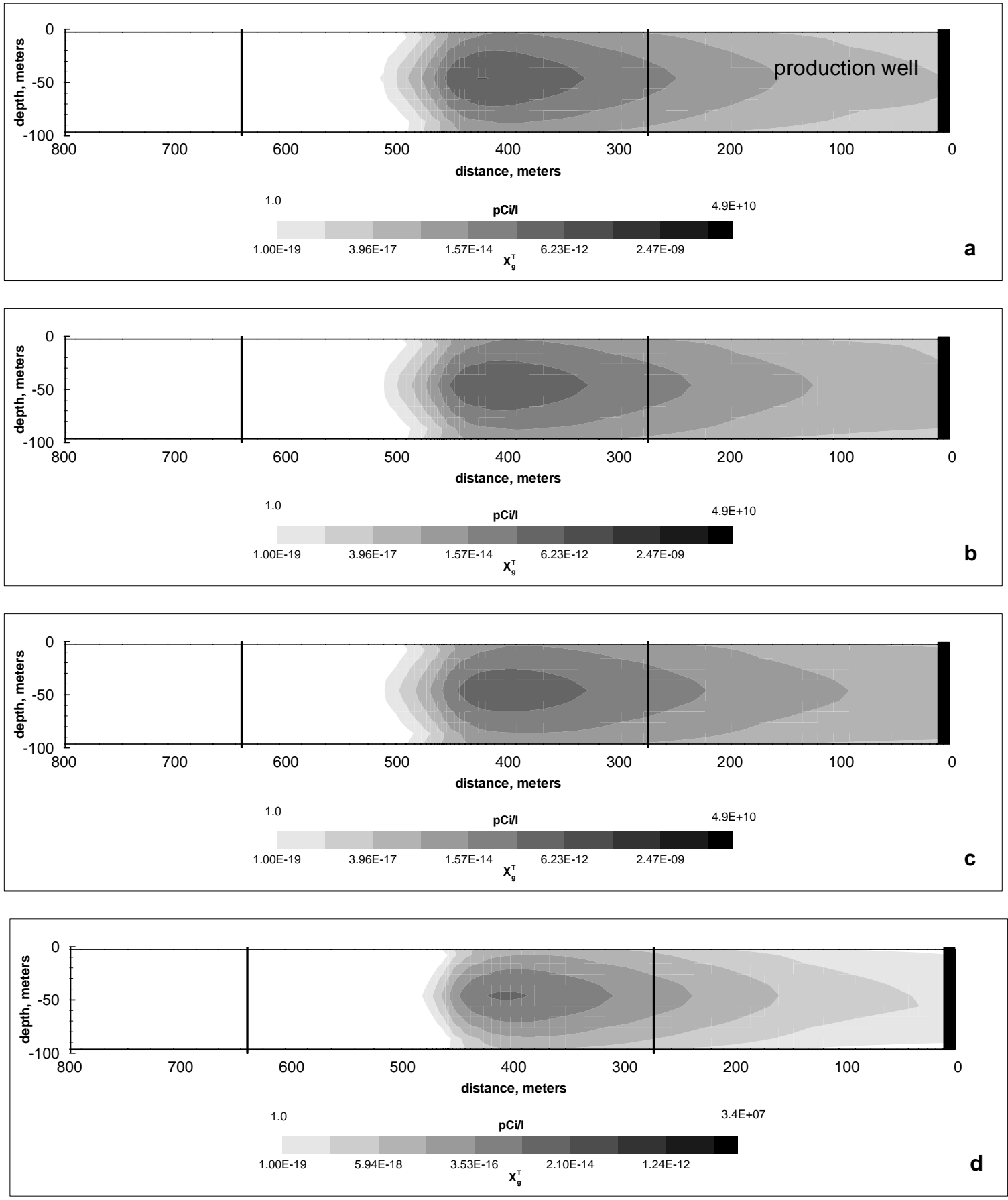

Figure 5. Tritium concentration in the gas phase after (a) 45 years, (b) 55 years, and (c) 65 years, after the detonation, with radioactive decay. Figure (d) shows tritium concentration in the liquid phase 65 years after the nuclear detonation. This simulation is different than those in the previous figures as the domain is homogeneous with $k=2.96 \times 10^{-14} \mathrm{~m}^{2}$ and the pumping rate is constant at $0.1 \mathrm{~kg} \mathrm{sec}^{-1}$. 